\title{
ESTUDIOS
}

\section{La vida pública, sus agentes y sus referentes éticos}

\section{Xabier Etxeberria ${ }^{1}$}

Palabras clave: Vida pública, agentes profesionales, ética cívica, política de principios.

Key words: Public life, professional agents, civic ethics, policy of principles.

\section{I.Aclaraciones iniciales}

Este escrito tiene como horizonte el tema de la ética en la vida pública. Es evidente que a la hora de apuntar a él el primer paso que se impone es definir con razonable precisión qué debe entenderse por "vida pública», por vida que se realiza en los espacios públicos. Una manera clásica de definir algo es marcando sus fronteras respecto a conceptos limítrofes. Es la estrategia que voy a seguir aquí. El concepto limítrofe más manifiesto en relación con nuestra categoría es, por supuesto, el de «vida privada»-la que se sitúa en el espacio privado-. Así expresada la tarea, parece fácil. Sin embargo, entiendo por mi parte que tiene una notable dificultad. Lo muestran las siguientes tesis que sostengo al respecto:

- La mera distinción entre vida pública y vida privada es excesivamente elemental para definir lo que significa e implica cada una de ellas. Esto es, se nos imponen distinciones más complejas.

- Las fronteras entre los espacios que distinguimos, sobre todo en lo que se refiere a su realización efectiva en la vida social y asumiendo la perspectiva sincrónica, no son nítidas sino porosas. Lo que significa en concreto que lo que inicialmente puede ser delimitado, por ejemplo, como situado en un determinado sector del espacio privado (así, una empresa mercantil), mostrará facetas relevantes que implican su real inserción en el espacio público.

\footnotetext{
${ }^{1}$ Profesor de la Universidad de Deusto.
} 
- Esta porosidad de fronteras entre espacios nos sugiere ya otra característica importante: la separación entre ellos no es separación en sentido duro, sino separación en interrelación. Saber concretarla como conviene es una tarea especialmente delicada y necesaria.

- Si asumimos la perspectiva no sincrónica sino diacrónica, tendremos que aceptar que las fronteras entre espacios son además móviles. Es decir, que relevantes ámbitos sociales que en un momento dado pudieron estar situados firmemente, por ejemplo, en el espacio público, en la evolución histórica acaban siendo situados en otro, evidentemente, porque ha cambiado el criterio de delimitación de espacios. El caso del ámbito religioso, en su expresión institucional, es particularmente expresivo: situado históricamente, en muchas culturas, incluida la nuestra, en el corazón del espacio público, hoy se reclama, al menos entre nosotros, que se ciña al espacio privado.

- El diferente enfoque en la definición de espacios no debe ser atribuido únicamente a procesos históricos intraculturales. Si adoptamos la perspectiva intercultural podremos constatar que, desde este punto de vista, la variedad de propuestas es notable. En unas culturas, especialmente en la occidental, hemos entrado firmemente y hace ya tiempo en la dinámica del «arte de la separación» (Walzer), en este caso de espacios. En otras, en cambio, se mantiene más un enfoque holista en el que las separaciones de espacios son muy relativas y además diferentes según las culturas. Lo que significa que la pretensión de universabilidad de una cierta distinción de espacios, que puede postularse por razones morales, tiene que confrontarse, con el respeto debido, con este dato.

Dados los límites que en una intervención como ésta tengo que autoimponerme, a la hora de definir en estas líneas el espacio y la vida pública tendré presentes especialmente las tres primeras tesis y me situaré en nuestro contexto cultural, decisivamente definido, por lo que a este tema se refiere, por los ideales de la modernidad ilustrada. Esto es, no abordaré los problemas históricos e interculturales de esta categoría ${ }^{2}$.

\footnotetext{
${ }^{2}$ He apuntado a este enfoque intercultural, aunque de modo indirecto y colateral, en el trabajo "La laicidad y sus retos en los nuevos contextos sociales: enfoque ético-político", aparecido en VV.AA. (2007) La laicidad en los nuevos contextos sociales. Estudio interdisciplinar, Santander, Sal Terrae, págs. 101-200. En ese texto presento ya la distinción de espacios que aquí desarrollo de modo más pleno, para aplicarla a la temática de la laicidad. En la medida en que propongo, en un momento dado, que puede haber encarnaciones legítimas plurales de ésta, apunto de paso a una apertura posible a inculturaciones diferentes en la constitución de los espacios públicos y privados, que puede estar legitimada con tal de que se respeten determinadas condiciones básicas ligadas a los derechos
} 
El que la definición de espacio y vida pública sea tan complicada y tan poco nítida puede motivar la reacción de declararla categoría inútil, incluso perjudicial. Por mi parte, voy a sostener que se trata de una categoría que sigue siendo decisiva para organizar adecuadamente la sociedad. Las distinciones no están encaminadas a enmarañar artificialmente el concepto, sino a mostrar toda su complejidad, para sostener a continuación que sólo haciéndonos socialmente cargo de ella logramos que se muestren moralmente eficaces. En definitiva, se trata de ser fiel a la complejidad de la propia la realidad, no de elaborar conceptos cartesianamente «claros y distintos» que no la tienen en cuenta.

¿Por qué, de todos modos, puede defenderse que se trata de una categoría decisiva? Porque tiene que ver con los valores morales fundamentales de libertad y justicia. La justificación ética de fondo que late en el esfuerzo por distinguir espacios sociales es la de encontrar las condiciones de posibilidad para que en la comunidad política se cumpla lo que se nos impone a todos -respeto a nuestra autonomía, justicia social-, a la vez que se respeta lo que debe ser reconocido como espacio para la creatividad de cada uno (sola o enmarcada en grupos voluntarios). Pues bien, esta distinción de espacios se nos muestra como una condición fundamental para que se realicen tales objetivos.

Decía, al comenzar, que el horizonte de estas líneas es el de la ética de la vida pública. De algún modo, quiere asentar sus prolegómenos. Precisé a continuación que lo que se nos imponía de arranque era delimitar como conviene el espacio público (con el trasfondo de las aclaraciones que acabo de hacer). La segunda tarea de cariz introductorio que debe hacerse, es la de identificar los agentes fundamentales que intervienen en él, aquellos que, propiamente, van a protagonizar la vida pública. Por último, convendrá cerrar el proceso argumental apuntando de modo genérico y esquemático los referentes éticos que pueden ser considerados especialmente relevantes para esos agentes. Queda luego, evidentemente, tener más explícitamente presentes a cada uno de esos agentes, para definir, también con más precisión, las orientaciones éticas que les son propias. Pero eso nos conduce ya a los terrenos que cabe situar, al menos análogamente, en la elaboración de éticas profesionales, aquello, precisamente, respecto a lo que se pretende que estas líneas sean un prolegómeno.

Voy a organizar mi labor expositiva en tres partes. En la primera dibujaré el mapa general de espacios y señalaré los diversos agentes que les dan vida. En la

humanos. Asumo de modo genérico la problemática ética de la diversidad cultural en (2004) Sociedades multiculturales, Bilbao, Mensajero. 
segunda, polarizándome en el objetivo que aquí me corresponde y apoyándome en ese mapa, me centraré en definir con más precisiones y desarrollos lo que debe ser considerada «vida pública» y los agentes que la protagonizan. En la tercera, propondré los objetivos y referentes éticos generales que estos agentes tendrían que tener especialmente presentes en su vida pública ${ }^{3}$.

\section{Los espacios socio-personales y sus agentes}

Acabo de sostener que la vida pública es la que tiene agentes, que habrá que precisar, en los marcos del espacio público. Y que este espacio, a su vez, lo voy a definir confrontándolo con los espacios limítrofes, en su complejidad y siendo a la vez consciente de las porosidades que pueden existir entre ellos. Esto lo materializo, en concreto, postulando de modo general la distinción de cinco espacios.

\section{I. Espacio privado de la intimidad}

Es el espacio para la espontaneidad de la autonomía personal situable en lo que llamamos "vida privada de la intimidad», esa vida que desarrollamos tanto en ámbitos de soledad estricta -cultivando procesos de interioridad-como en ámbitos definidos decisivamente por su carga afectivo-relacional.

Se trata de un espacio que podemos reclamar y gestionar moralmente a partir del derecho/respeto a la privacidad (en el sentido de "retiro a lo privado»). Como tal, implica el derecho a que lo que se hace en él permanezca oculto a las miradas de quienes no son invitados a él. Su metáfora (y con mucha frecuencia, su espacio físico real) es, por eso, la «casa», la morada o vivienda capaz de cobijar esa intimidad.

Los agentes de este espacio están ya sugeridos en su propia definición. Para empezar, todo individuo humano en sus autodelimitaciones de soledad. En segundo lugar, los grupos de amigos y las parejas afectivo-sexuales, con sus relaciones correspondientes. En tercer lugar, de modo más complejo, las familias: éstas son,

\footnotetext{
${ }^{3}$ Como pequeña muestra bibliográfica para que el lector pueda completar y confrontar lo que aquí se dice, propongo los textos siguientes: Daniel INNERARITY (2006) El nuevo espacio público, Madrid, Espasa; Will (1995) Filosofía política contemporánea, Barcelona, Ariel [capítulo dedicado a los feminismos]; José Miguel MARINAS (coord.) (2005) Lo íntimo y lo público. Una tensión de la cultura política europea, Madrid, Biblioteca Nueva; John RaWLs (2001) El derecho de gentes y «una revisión de la idea de razón pública», Barcelona, Paidós [el segundo trabajo].
} 
indudablemente, ámbito decisivo de la intimidad afectivo-relacional, pero a través de su marcada institucionalización, tienen conexiones significativas con la dinámica de la vida pública.

\subsection{Espacio público fisico}

Históricamente, la primera acepción de "vida pública» tenía que ver con vida expuesta a la mirada de los otros, abierta a su correspondiente enjuiciamiento -moral o del tipo que fuera ${ }^{4}$. Hoy esta acepción sigue funcionando, aunque con nuevos tonos. Como tal, tiene su espacio propio, al que conviene llamar "espacio público físico». La metáfora que lo simboliza, y que en buena medida lo materializa, es ahora la de la "calle». Se supone que lo que hacemos en la calle está bajo la mirada y juicio de los otros, sin que podamos reclamar ningún derecho a la intimidad.

Los nuevos tonos de esta versión tradicional de espacio público físico tienen que ver con lo siguiente. Primero, aunque se reconozca el derecho a que se hagan juicios, se insiste en que tienen que hacerse en el marco del respeto a la legitimidad cívica de toda conducta que no dañe los derechos de los otros. En segundo lugar, se enfatiza más que antes que la visibilidad no es sólo una molestia que hay que soportar, sino un recurso que cabe aprovechar para perseguir determinados objetivos: piénsese en las procesiones religiosas, en las manifestaciones de masas con motivación política, en los gestos simbólicos de unos pocos llamados a difundirse gracias al eco mediático, etc.

Esto último nos lleva a otra modalidad actual de este espacio público «físico». Lo físico tiene que ser concebido tanto en su sentido más tradicional -geográfico-, como en su sentido "virtual» y «mediático». La "calle» es ahora, en medida muy relevante, el espacio múltiple de los múltiples medios de comunicación o la página

\footnotetext{
${ }^{4}$ De ahí viene, por supuesto la calificación a las mujeres prostitutas como mujeres "de vida pública»: estén físicamente en casas o en la calle, se las considera por definición expuestas a la mirada de cualquiera, quedando enmarcada su actividad sexual no en la intimidad de la morada y en un marco relacional privado-afectivo, sino en la lógica público-visible del comercio. El juicio correspondiente, marcadamente hipócrita con frecuencia, era, por supuesto, muy negativo. Se ha subrayado, con pertinencia y como ejemplo de lógica discriminatoria de género, que cuando se ha adherido socialmente a los varones el calificativo de público, para hablar de "hombres públicos», ha sido, en cambio, sobre todo para subrayar su presencia en lo que luego quedará definido como espacio público-político institucionalizado y en cualquier caso para enmarcar su actividad en espacios de visibilidad que merecen en cuanto tales juicio laudatorio.
} 
accesible de internet ${ }^{5}$. Esta última, hay que advertir, con notables porosidades: puede ser el soporte tanto de búsquedas cargadas de intimidad relacional como de amplificaciones de visibilización a cualquier parte del mundo ${ }^{6}$. Esta potenciación de visibilización, propia de lo mediático y lo virtual, actúa en las dos direcciones señaladas: como amenaza respecto a aquello que queremos mantener en la intimidad y como oportunidad respecto a aquello para lo que queremos máxima "publificación"7.

Lo que voy apuntando permite extraer la conclusión de que este espacio público físico es, en realidad, el espacio físico en el que, desbordándose la vida privada de la intimidad, se puede realizar la vida propia de los otros espacios como tal inmateriales que van a precisarse a continuación. Todos son espacios con vidas propias que precisan cierta visibilización, aunque sea en formas diferentes (recuérdense, pensando sólo en la calle en su sentido físico, los ejemplos que antes he citado de una procesión religiosa, una manifestación de motivación política o un gesto simbólico, a los que pueden añadirse los de su utilización para la movilidad, o como ámbito de fiesta, o lugar para el comercio, etc.). Por eso precisamente se impone una regulación de este espacio físico de "publificación", lo que nos remite a las autoridades del espacio público-político en su sentido más estricto, que habrá que definir luego.

Las precisiones en torno a este espacio nos vuelven a especificar implícitamente sus agentes: van a ser todos los que vayan apareciendo en los espacios restantes, puesto que salvo el agente del espacio de la intimidad, todos los demás, para realizar sus objetivos, tendrán que hacerse presentes, de un modo u otro en este espacio físico-virtual que les visibiliza. De ahí la relevancia moral de su adecuada regulación.

\footnotetext{
${ }^{5}$ Curiosamente, está habiendo una marcada tendencia a «publificar-visibilizar» a lo grande, en esta "calle mediática» que es la televisión, lo que se presupone corresponde al espacio de la intimidad (reality shows, cotilleos varios, etc.).

${ }^{6}$ De ahí la distinción, no fácil de gestionar, entre páginas cerradas y abiertas. Y entre páginas cerradas por estricto motivo de intimidad y parcialmente cerradas por motivos de comercio, que tienen que ver más con lo que se va a considerar luego como espacio privado de la vida civil.

7 El mundo, hoy tan relevante, de la «publicidad» es en realidad ese mundo que persigue que determinadas ideas, o personas, o productos aparezcan lo máximo posible en este espacio público físicomediático que los visibiliza.
} 


\subsection{Espacio privado de la iniciativa civil}

Hasta ahora ha aparecido una vida privada, de la intimidad, situada en su propio espacio, que se ha enfrentado a una vida pública, la de la visibilidad, que tiene también el suyo. Pero la modernidad va a plantear, sin negar lo precedente, otra concepción de lo privado/público que precisa que se les reconozcan espacios específicos. En ella el criterio de discernimiento cambia: va a ser pública toda actividad que tenga que ver con el interés o bien común, concebido como la convivencia en libertad y justicia, y va a ser privada toda actividad que persigue intereses legítimos pero no impositivamente obligantes.

Es a partir de este nuevo criterio como aparece el que puede ser llamado espacio privado de la iniciativa civil. Se corresponde con el espacio de las interacciones sociales amparadas en la autonomía privada de las personas, con las que se persiguen objetivos no enmarcables en ese interés general o bien común. Su referencia justificadora es el conjunto de derechos civiles que remiten a las libertades que, en este sentido, podemos llamar también civiles.

Las interacciones que son posibles en este espacio son numerosísimas, por supuesto. Pero conviene destacar dos grandes tipos entre ellas. Por un lado, tenemos las interacciones mercantiles, aquellas que implican valoración económica de lo intercambiado (bienes en cuanto recursos para algo), buscándose en principio un equilibrio. Por otro lado, tenemos las interacciones en forma de comunicaciones en torno a los mundos de sentido, en las que se persigue difundir y compartir lo que se concibe como sentido de la realidad. Por supuesto, caben, en la práctica social, intersecciones entre los dos tipos de iniciativas.

Estos dos tipos de interacciones nos conducen a los agentes más relevantes en este espacio. En principio, toda persona humana, en cuanto individuo que quiere tener una iniciativa en el espacio civil, es potencial agente del mismo. Y todos, de hecho, lo somos en múltiples gestos cotidianos, por ejemplo, en el grueso de nuestras actividades como consumidores. Ahora bien, hay dos tipos de agentes que tienen especial relevancia, y que tienden a expresarse como organizaciones que habrá que calificar de "privadas»: las empresas mercantiles y las comunidades de sentido. Las empresas mercantiles son, por supuesto, las que más relevantemente protagonizan las interacciones mercantiles, las que, además, acaban incluyendo a un gran número de individuos, no sólo por su participación interna en ellas, sino en cuanto clientes y consumidores de sus bienes y servicios. Por su parte, las comunidades de sentido pueden ser religiosas o seculares, aunque de hecho, las que manifiestan más protagonismo organizado son las primeras, con sus agentes 
individuales que tienen que ser calificados ahora como creyentes (sitúese aquí a todas las confesiones religiosas, con su correspondiente organización).

La propia definición y justificación de este espacio pide que todas estas empresas y comunidades se enmarquen en el pluralismo de propuestas, ofrecidas en cuanto tales a las libertades de las personas. Y es a partir de aquí precisamente como aparece la conexión con el espacio público que enseguida precisaré: es desde éste (desde sus instituciones, pero también desde la ciudadanía) desde donde habrá que garantizar el control que se precisa para que las iniciativas privadas de las que estamos hablando: 1) no contradigan los intereses generales; 2) específicamente, no atenten contra las libertades individuales.

A su vez, no habrá que descartar la posibilidad de que estos agentes del espacio privado de la iniciativa civil, queriéndolo o sin querer, tengan incidencia expresa en el espacio público, lo que vuelve a mostrar la porosidad de fronteras que presupuse al inicio ${ }^{8}$.

\subsection{Espacio público-político institucionalizado}

El criterio al que he hecho referencia en la presentación del espacio anterior nos delimita, por contraposición, al que conviene llamar «espacio público-político institucionalizado». Es el espacio en el que se ejerce la participación política en vistas a la organización de la convivencia social, el espacio de acción común de las personas definidas como ciudadanas, el espacio que tiene como referencia para su dinamismo interno (en la forma de inspiración y de horizonte) al interés general o bien común.

Los derechos a los que remite y que a la vez lo justifican son el conjunto de derechos, pero especialmente los llamados políticos o de participación pública y los derechos sociales, cuyo disfrute garantiza no sólo la satisfacción de las necesidades

\footnotetext{
${ }^{8}$ Hay que contemplar aquí el delicado tema de la gran influencia que, fácticamente y debido a su gran poder, ejercen las grandes empresas en las decisiones que se toman en el espacio público, se lo propongan directamente o no, hasta el punto de poder generar ámbitos de corrupción. Piénsese, por ejemplo, en la gran banca privada. El control público de ellas, que se impone, el forzarlas a mantenerse en su espacio propio sin quebrantar derechos, resulta difícil. Cabe, de todos modos, combinada con el necesario control, otra vía a la que me referiré más adelante, que se sitúa en el marco de la "gobernanza»: la de invitar a las empresas a que se abran, a su modo y en medida razonable, al interés público. Una muestra más de la porosidad de las fronteras entre espacios, pero porosidad que debe ser controlada por las instituciones públicas democráticas.
} 
básicas, sino también las posibilidades tanto de esa participación pública como de la actividad libre en el espacio privado de la iniciativa civil.

El que en este espacio se apunte al interés general o bien común presupone que se dan una serie de significaciones compartidas por parte de todos los ciudadanos, que van más allá del mero equilibrio de intereses particulares y que les integran a todos en una comunidad política, por encima de las diferencias que puedan querer cultivar en el espacio de la intimidad o de la vida civil. Hay que observar, con todo, en relación a esto, que caben enfoques diversos de este fondo común, que, en la práctica de las sociedades, tienden a ser más acentuaciones de una perspectiva que opciones excluyentes:

- En el enfoque liberal lo que se destaca como bien común es facilitar la coordinación de los intereses individuales y grupales desde consensos mínimos sobre lo justo, concebido como la no obstaculización directa de la autonomía privada y pública de las personas. Tendencialmente, esto significa que este espacio público es puesto al servicio del espacio privado de la iniciativa civil.

- En el enfoque republicano se propugna un identificación no instrumental con la polis, con su bien público y su historia, estimulándose el correspondiente deber intenso de participación, alentado por las virtudes cívicas, en vistas a la clarificación y realización de los intereses generales. Puede decirse que aquí es lo privado lo que se pide que esté al servicio de lo público.

- Por último, en el enfoque más propiamente comunitarista, se resalta la identificación del ciudadano con la cultura nacional. Con lo que lo público, en un sentido, incluye esta identidad cultural y, en otro, está al servicio de la misma.

No voy a entrar aquí, porque no es su lugar, en el debate en torno a estos enfoques. Me limito a subrayar lo que ya he adelantado: debería tenerse como referente para este espacio, el conjunto de los derechos humanos en su interdependencia e indivisibilidad. Desde este criterio moral se pueden criticar liberalismos extremos y comunitarismos cerrados. Lo cual no suprime el pluralismo al que está abierto este espacio, que tan plásticamente se expresa en la diversidad de partidos políticos: todos ellos tienen que compartir un fondo prepartidario en torno a valores y procedimentalismo democrático (para la deliberación y la decisión), pero pueden disentir en concreciones más precisas del interés general, generando la correspondiente conflictividad (con sus ventajas y sus riesgos).

Pasando a los agentes que protagonizan el espacio público-político institucionalizado, cabe especificarlos del siguiente modo: 
- Están, para empezar, todas las personas, en igualdad de reconocimiento ly, deseablemente, de condiciones básicas) constituidas como ciudadanas, esto es, como sujetos de autonomía pública que se ejerce a través de la participación en este espacio público.

- En segundo lugar, definidos por su dedicación más específica a este espacio y por su sometimiento a la voluntad popular, están los "políticos», enmarcados institucionalmente de dos modos: 1) en los partidos políticos; 2) en las instituciones públicas en toda su variedad, pero en cuanto "elegidos», ya sea directamente por los ciudadanos, ya sea indirectamente por quienes han sido elegidos por los ciudadanos; pueden ocuparse en tareas de legislación, de gobierno ejecutivo o de administración.

- En tercer lugar, están los funcionarios y trabajadores que, por méritos profesionales se insertan en las instituciones públicas, en calidad de "expertos» para las tareas asignadas. Se les ha definido como personas llamadas a estar al servicio objetivo -no discrecional- de los intereses generales, de acuerdo a las leyes. Puede incluirse aquí, de forma especialmente relevante, a todos los que componen el sistema judicial, pero por supuesto hay muchos más. Como cabe suponer, es muy importante y a la vez enormemente delicado, para el servicio al bien común, encontrar la correcta «separación en relación» entre políticos y funcionarios.

- Por último, cabe hablar de un sujeto colectivo: el Estado como tal en cuanto «pueblo» que decide democráticamente-soberanía popular-, que puede incluir unidades subestatales y aspirar a constituir unidades supraestatales.

\subsection{El espacio social}

El criterio por el que se hace la distinción entre los dos últimos espacios -la diferente referencia al interés general-admite un espacio específico más, que entiendo es importante: el que cabe llamar «espacio social». A primera vista puede ser considerado un mixto de los dos anteriores: como en el público, expresa una participación y un compromiso social orientados al logro de los intereses generales; como en el privado, no media la representación o elección democrática. Esto último significa que no está enmarcado en las instituciones del Estado, sino que se plasma en organizaciones de la sociedad civil. Pero a diferencia de las organizaciones civiles situables en el espacio privado, arrincona tanto la lógica mercantil de algunas de ellas como la orientación de sentido y cosmovisional particular de otras. Puede 
decirse, por eso, que en él anida una tensión entre lo privado y lo público, aunque personalmente considero que se trata de un espacio en el que debe enfatizarse su orientación a lo público tomado en sentido amplio.

Los agentes que protagonizan este espacio social son de varios tipos:

- En primer lugar, tenemos a aquellas organizaciones sociales que, por su propia definición y estrategia, deben ser situadas de modo pleno en este espacio. Están aquí los movimientos sociales organizados (los ya clásicos de feminismo, pacifismo, ecologismo, pero también otros), con tal de que se remitan estrictamente a los derechos humanos - debiendo aceptarse que están en debate interpretaciones diversas de los mismos en estos campos-. Y están también las que llamamos ONG, cuando se definen exclusivamente por su compromiso con algún derecho humano.

- En segundo lugar, caben en este espacio organizaciones que desde el punto de vista de las personas a las que convocan pueden ser consideradas gremiales (lo que las situaría en el espacio privado de la iniciativa civil, con sus intereses legítimos pero particulares), pero que se plantean también -a veces sobre todo- objetivos que pueden ser calificados sin duda como orientados al interés general. Deben ser situadas en este espacio social sólo en la medida en que se los plantean (lo que significa que pueden situarse en los dos espacios, según sus objetivos). Es el caso de algunos colegios profesionales capaces de superar el corporativismo o de ciertas luchas sindicales que persiguiendo mejoras laborales lo hacen de tal modo que persiguen en realidad la realización para todos del derecho al trabajo y en el trabajo.

- En tercer lugar, pertenecen también a este espacio social organizaciones e iniciativas enmarcadas en instituciones situadas, por su identidad más propia, en el espacio privado de la iniciativa civil, pero orientadas en cuanto tales a la realización del interés general, de algún derecho humano. Esto es algo común en instituciones religiosas (piénsese, por ejemplo, en Cáritas); $y$, en teoría al menos, también puede darse en instituciones mercantiles. Las condiciones para que pueda considerárselas legítimamente en este espacio son: que realicen su actividad pro bien común con imparcialidad (no subordinándola estratégicamente a los intereses propios de la institución "madre", ya sean de sentido, ya sean comerciales); que tengan suficiente autonomía; que no haya contradicción entre lo que se persigue como institución privada y lo que se persigue con las iniciativas sociales.

Esta variedad de agentes vuelve a mostrar la porosidad de las fronteras entre espacios, la flexibilidad que se da en ellos a la hora de verlos actuando en la 
sociedad. Además, hace también manifiesto que el gran reto para los agentes en este espacio es el de ser fieles a esa tensión que anida en él: no deben considerarse representantes democráticos, porque no lo son, y a su vez pueden reclamar a todos los efectos que trabajan por el bien público, pero con tal de que sean coherentes con ello.

\section{La vida pública y sus principales agentes}

Dibujado el mapa general de espacios, con sus correspondientes agentes, toca ahora definir con precisión, y a partir de ellos, la vida pública y sus agentes propios.

\section{I. Sobre la delimitación de la vida pública}

Considero, para empezar, que la vida pública debe identificarse decisivamente no con la vida expuesta a las miradas de los demás (mero criterio de visibilización), sino con la que se protagoniza en el espacio cívico en el que nos ocupamos de los intereses generales y de la organización socio-política de la convivencia (prevalencia del criterio de los objetivos perseguidos).

Para delimitarla con más precisión, conviene hacer una breve referencia al surgimiento moderno de este término. La modernidad, en efecto, va a ir elaborando una distinción enormemente significativa entre «vida civil» o «sociedad» y «vida política» o «Estado», que cuaja con la revolución industrial y la caída del Antiguo Régimen. Vida pública sería propiamente la que gira en torno al Estado.

Conceptualmente, consagra la distinción Hegel, con las categorías de «sociedad civil» (distinguiéndola ya del cuerpo político) y «Estado». Recordemos que, según él, en la «vida ética»: 1) la familia, con sus lazos naturales y su eticidad propia, 2) es «negada» por la sociedad civil de individuos que persiguen sus intereses privados instrumentalizando al Estado, 3) que a su vez es «negada» por el Estado, en el que se unifica lo privado y público, lo individual y lo universal.

¿Cómo reasumimos hoy estas conceptualizaciones? Normalmente, incluimos en la sociedad civil los que antes he llamado «espacio privado de la vida civil» y «espacio social». ¿Habría que identificar a lo que en ellos se hace con vida privada y sólo a lo que se hace en el «espacio público-político institucionalizado» con vida pública? Priorizando el criterio de orientación a los intereses generales, entiendo más adecuada esta otra distinción: 
- Entender por «vida privada» la que se enmarca en los que he llamado "espacio privado de la intimidad» $y$ «espacio privado de la iniciativa civil».

- Entender por «vida pública» la que se enmarca en la articulación de los que aquí he considerado "espacio público-político institucionalizado» y "espacio social».

Esta propuesta supone agrandar lo que hay que considerar vida pública. Pero incluso hay razones para agrandarla algo más. Están ligadas a las actuales fragilidades del Estado, el encargado de liderar-que no monopolizar- la vida pública. Son fragilidades relacionadas con tres fenómenos en especial: el impacto de la globalización, con el decisivo poder de las empresas transnacionales, con frecuencia superior al poder políitico; el de la individualización9, que pone en crisis las tradicionales propuestas de participación e identificación con la comunidad política; el de la diversidad intraestatal, que desborda el clásico pluralismo implicando reclamaciones de Estados plurinacionales y pluriétnicos.

Pues bien, ante la crisis que ello supone, que implica crisis del ideal del «Estado social de derecho»-mejor que «Estado de bienestar»- en el que lo público institucional estatal adquiere su máximo esplendor (hasta el punto de reclamar su identificación con lo público en cuanto tal), se está proponiendo, frente a la vuelta a la solución del «Estado mínimo» intentada por el neoliberalismo de los ochenta, el «Estado activador», la "gobernanza». Esta implica acciones concertadas-cooperativas entre actores públicos y privados, que puede suponer que no sólo se integran en el espacio público los agentes del «espacio social», sino que, a su modo y con sus límites, se integran también agentes del «espacio privado de la vida civil»-como las empresas o incluso los consumidores concienciados- a los que se pide abrirse al horizonte del interés público ${ }^{10}$. En este sentido, puede decirse que inciden en la vida pública, que hoy, como puede verse, se ha "complejizado" fuertemente.

\subsection{Sobre los principales agentes de la vida pública}

De las consideraciones precedentes se desprende una lista de agentes de la vida pública ciertamente abultada. Hay que incluir entre ellos, sin que precise volver a consignarlos aquí, a todos los que han sido situados tanto en el espacio público-

\footnotetext{
9 Se describe bien este fenómeno en U. BeCK y E. BeCK-GeRNSHeIm (2003) La individuación. El individualismo institucionalizado y sus consecuencias sociales y políticas, Barcelona, Paidós.
}

${ }^{10}$ Una buena presentación de todo esto se encuentra en el citado libro de Daniel Innerarity. 
político institucionalizado como los que han sido señalados en el espacio social ly con los matices correspondientes, los que son llamados a colaborar en la gobernanza y en la medida en que colaboran en ella).

Hay, además, un agente, que hasta ahora ha permanecido oculto, que conviene destacar por su gran importancia. Se trata de los medios de comunicación. Se muestran especialmente dúctiles a la hora de situarse en los espacios público, social y privado, porque:

- Ofrecen un ámbito y unos materiales (noticias, foro de opiniones) que son decisivos para las dinámicas de la vida pública, las ligadas en especial a la participación política; sin ellos la ciudadanía carece de referencias. Puede incluso decirse que, al menos por las intenciones y la justificación social de su nacimiento, cabe situar en ellos su bien interno. En la medida en que se trata de medios de propiedad privada, pueden ser situados, desde este punto de vista, en el espacio social. Y por supuesto, si son estatales, se sitúan por definición en el espacio público-político institucionalizado.

- Pero cumplen esos objetivos, de manera abrumadora, bajo la presión de la ganancia económica y del éxito en la captación de usuarios; mezclándolos, además, con objetivos de entretenimiento que pueden desnaturalizar a los primeros. Esto supone, en su conjunto, una marcada tendencia a someter a lógicas de privacidad a lo público y a "publificar" lo privado, bien estudiada por diversos analistas, lógicas que deforman ambos espacios desde la priorización del interés particular.

Desde este punto de vista, trabajar por que los medios, en sus diversos formatos, sean realmente agentes intervinientes honestos en el espacio público, pasa a ser una tarea de primer orden.

\subsection{Sobre la consideración de algunos agentes como agentes profesionales}

Al comenzar estas líneas indiqué que se situaban en la perspectiva de la ética de la vida pública, abierta en lo posible a la lógica de la ética de las profesiones. Dado que éstas afectan a agentes específicos - a los colectivos profesionales diversos-, sería éste el lugar en el que preguntarse qué agentes públicos, entre los señalados, son susceptibles de ser contemplados como candidatos para elaborar éticas profesionales, éticas de profesiones que se ejercen en la vida pública. $A$ modo de mero apunte, señalo al respecto lo siguiente. 
- Cabe situar aquí a los «políticos», en el uso social habitual de esta palabra y, por tanto, a la política como profesión, identificada con la gestión del poder público mediado directa o indirectamente por la elección democrática.

- Tienen también su lugar propio los funcionarios, en concreto, la dimensión profesional de la funcionarización que es compartida por los diversos profesionales que se sitúan como expertos en la función pública. Podría plantearse, de todos modos, si conviene distinguir entre ellos. Concretamente, entre los que podemos percibir dominantemente como funcionarios y aquellos que, aun siendo funcionarios, los percibimos sobre todo como profesionales de su especialidad (piénsese, por ejemplo, en los educadores y en el personal sanitario que están en instituciones públicas). Si la distinción fuera pertinente, a la hora de elaborar la ética profesional de los funcionarios habría que pensar fundamentalmente en los primeros.

- En principio, cabría enfocar la profesión periodística como profesión de la vida pública, concebida ésta en su sentido amplio. Si la opción es discutible, lo que no es discutible, creo, es enfatizar la decisiva vertiente pública de esta profesión, cuando se estudia la ética propia de la misma.

- Esto último, generalizándolo, lleva a plantearse la posibilidad de completar las aproximaciones a éticas profesionales del espacio público, con un trabajo general sobre «la ética de la vida pública», pensado para el conjunto de agentes de la misma, que podrían tener como referencia, para incorporar a sus propias éticas, los agentes no fácilmente identificables como profesionales estrictos de lo público (piénsese en los agentes de las ONG, por ejemplo), y en general el conjunto de los profesionales que deben descubrir la vertiente social de su profesión. Detectar las «profesiones de lo público» no debe significar olvidar «la dimensión pública» del conjunto de las profesiones.

\section{Objetivos y referentes éticos para los agentes de la vida pública}

Tras el recorrido hecho en los apartados precedentes, sólo queda, para completar el esquema anunciado al comienzo, ofrecer los objetivos y referentes éticos que deben tener en cuenta los agentes de la vida pública. Ya indiqué que los voy a plantear en apunte y de modo genérico, como no puede ser de otro modo, pues sólo cabe exponerlos de forma detallada y específica cuando se abordan en relación con la condición propia de cada agente. A estas observaciones añado 
ahora la de que no pretendo ninguna exhaustividad en la relación que propongo. Hela, pues, aquí.

Se impone, en primer lugar, impulsar la colaboración de todos en la definición dialógica del bien común integrador y en su asunción coherente:

- Precisando, para empezar, los implicados en él, que no deben ser sólo todos los ciudadanos presentes, sin discriminaciones. Hay que abrirse a los derechos de las generaciones pasadas (en especial en forma de memoria y reconocimiento de las víctimas) y también a los de las generaciones futuras (sobre todo como derecho a recibir un contexto ecológico, un medio ambiente, adecuado).

- Teniendo presentes, en equidad, las diferencias que, porque sus portadores las consideran una riqueza o un rasgo de identidad, quieren mantenerlas. Discerniendo las que cabe defender únicamente con los clásicos marcos del pluralismo -diferencias sin presencia en la vida pública-, y aquellas que pueden precisar legítimamente amparo y presencia pública. Siempre, por supuesto, que se trate de diferencias que se reivindican sin dañar los derechos de los demás.

- Distinguiendo adecuadamente entre valores privados de individuos y grupos - que deben ser respetados-, y valores públicos -los sujetos a la deliberación y decisión democrática- que deben ser fomentados por las instituciones de todos. Siendo conscientes, siempre, del legítimo pluralismo al que están abiertos.

- Afrontando como corresponde, en los actuales marcos de globalización, que los límites geográficos para la justicia distributiva -dimensión decisiva del bien común- no pueden reducirse a los del propio Estado, que hay que avanzar en la creación de instituciones internacionales que garanticen una distribución de bienes básicos para todos los humanos en función de sus necesidades.

En segundo lugar, hay que ensamblar este bien común así delimitado, con la ética cívica que emerge de los derechos humanos tomados en su interdependencia e indivisibilidad, constituyéndola en referencia normativa de la vida pública y de sus diversas instituciones.

En tercer lugar, hay que trabajar por garantizar el adecuado funcionamiento del procedimentalismo democrático, tanto en la deliberación como en la decisión concerniente a los asuntos de interés común, enfatizando el deber de participación.

Un cuarto aspecto que conviene tener muy en cuenta, especialmente para lo que se llama de modo más estricto «vida política», es fomentar la búsqueda de articulación 
de lo que cabe definir como "política de los principios»-la que pretende remitirse a los derechos humanos-, con la «política de los sentimientos»-la que gestiona positivamente los afectos colectivos ligados a las pertenencias a los grupos sociales, para que no degeneren en manipulaciones y en conflictos violentos-, y con la "política de la prudencia» - la que a la hora de las decisiones tiene en cuenta las circunstancias y las consecuencias-.

Es precisamente en ese momento cuando aparece el quinto referente que conviene subrayar. En la vida política toca responsabilizarse por las consecuencias en relación al bien común, a cada uno en función del lugar que ocupe ly recuérdese que todos ocupamos al menos el lugar de ciudadanos). Puede plantearse, de todos modos, que para los que consideramos "políticos» en sentido estricto, la exigencia de responsabilidad sería mayor: no sólo por su mayor poder, sino porque no se trataría únicamente de la responsabilidad moral, la que pide tener en cuenta las consecuencias previsibles; estaría abierta a la responsabilidad política, la que debe asumir las consecuencias negativas imprevisibles, por ejemplo, en forma de dimisión del cargo.

Pensando más en concreto en los funcionarios, tienen que hacerse cargo de lo que ha sido denominado "derecho de los ciudadanos a la buena administración", que pide que sea: imparcial, equitativa, en tiempo razonable y argumentada. Enfrentándose siempre a la inercia administrativa.

Por último, ya Jonas nos advirtió de un riesgo que afecta a la vida política regida por procesos democráticos pautados con ritmos temporales breves: el de dejarse dominar por el inmediatismo de la elección siguiente y de la satisfacción de las reclamaciones puntuales del presente, hechas por los colectivos que mejor pueden hacerse oír. Supone incidir en una grave irresponsabilidad respecto al futuro no inmediato. Hay que exigir a los políticos que no caigan en esta trampa, pero sin olvidar que en última instancia caen en ella porque se encuentran con unos ciudadanos que no asumen sus deberes de solidaridad intrageneracional e intergeneracional.

Cierro estas líneas recordando que una ética de la vida pública así expresada, afecta ciertamente a los protagonistas de ella socialmente más visibles, pero afecta igualmente al conjunto de las profesiones - a cada una a su modo- $y$ a todos nosotros en cuanto ciudadanos. Apuntando, además, a algo que es decisivo para todos: el bien común o interés general. Tendremos que comenzar, por eso, por no desentendernos, nadie, de ella. 